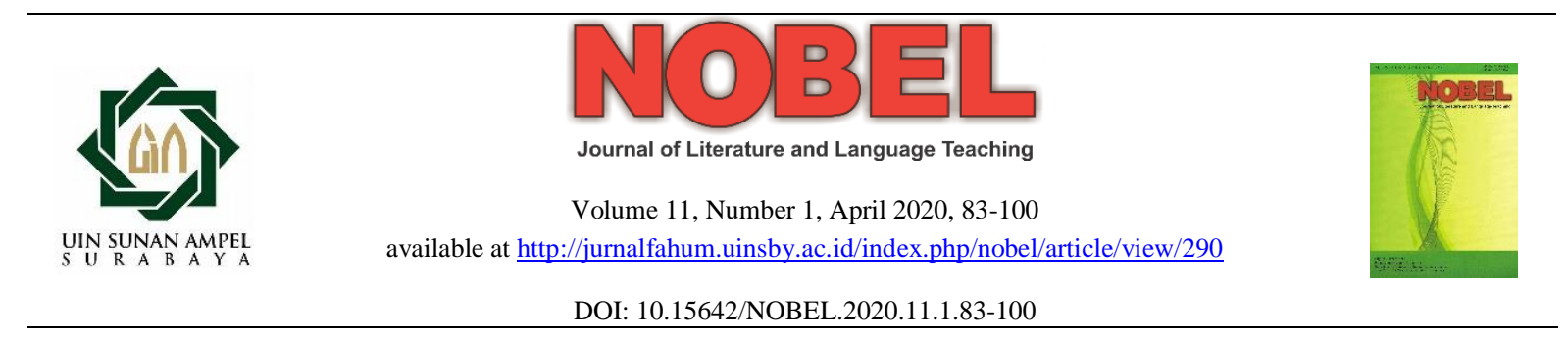

\title{
ASSERTIVE SPEECH ACTS PERFORMED BY TEACHER IN EFL CLASSES
}

\section{A. Dzo’ul Milal ${ }^{1 \bowtie}$, Wahju Kusumajanti ${ }^{2}$}

UIN Sunan Ampel Surabaya ${ }^{1}$, Jalan A. Yani 117, Surabaya, Indonesia UIN Sunan Ampel Surabaya ${ }^{2}$, Jalan A. Yani 117, Surabaya, Indonesia

\begin{tabular}{l}
\hline Article Info \\
\hline Article History: \\
Received February 2020 \\
Accepted March 2020 \\
Published April 2020 \\
\hline Keywords: \\
Assertive acts, language \\
functions, target language \\
competence \\
\hline
\end{tabular}

\begin{abstract}
One of the factors affecting language teaching and learning is the way how the communication process between teacher and learners takes place in the classroom. In a language instructional context, the teacher's language serves several functions: transactional, interactional, regulatory, as a language model, and linguistic input. These multiple functions give rise to the performance of varied speech acts. This paper tries to reveal the variety of assertive acts and how they are performed by the teachers. After the data were collected by observation and recording and analyzed using a qualitative technique, it was revealed that the assertive speech acts are realized in terms of informing, describing, exemplifying, explaining, concluding, summarizing, commenting, responding, extending, giving feedbacks, giving clues, announcing a topic, announcing a task, and controlling/shifting a topic. The performance of those acts is always consistent with the main purpose of EFL, i.e., elevating the learners' competence (knowledge and ability) of the target language.
\end{abstract}




\section{INTRODUCTION}

The role of teachers and learners in communication is asymmetrical (Stubbs, 1983:43) in the sense that it is the teacher who has the power, authority, and control over the learners. Although there is a trend recently towards the learner-centered approach, the teacher still has the responsibility to transform knowledge, manage the class, organize the teaching and learning process, and facilitate learners' learning. Consequently, teachers do much of the classroom talking, such as opening the class, motivating the learners, presenting materials, explaining concepts, managing the class, advising, providing assignments, and closing the class.

In conducting classroom communication, teachers use language to serve several functions. Referring to Brown and Yule's categories (1983:1), teachers' language serves transactional function because communicants-teacher and learners-focus on the conveyance and/or perception of ideas. The teacher presents instructional materials, explains concepts, and provides information to make learners perceive and comprehend the points. Teachers should also establish and maintain social relationships with the learners to lower the affective filter of the learners (Krashen, 1985), thus creating a conducive learning environment. In that case, language is used to serve the interactional function.

Teachers' language also serves a regulatory function (Halliday, 1975:11) because using the language, the teacher controls and manages the class proceedings. It also plays a significant role as a model to imitate (Ellis, 1986; Brown, 2007) and invaluable input (Krashen, 1985) to promote language acquisition. Especially in the context of English as a foreign language, teachers' target language speech may become the main source of comprehensible input. In sum, it is used not only to communicate but also to train the learners to communicate.

Regarding those multiple functions, it is interesting to reveal what the teacher discourse is like as manifested in terms of speech acts. Blum-Kulka (1998:43) quoting Searle (1979) cites that "Though there seems to be an endless number of illocutionary acts, such acts may be grouped into five main types, namely assertive, directive, commissive, expressive, and declarations." To limit the scope of discussion, this study is focused on the assertive speech acts performed by teacher because this act, such as clarifying, explaining, exemplifying, justifying, is the core of pedagogical communication and relevant with the teaching and learning process as to improve the cognitive competence of the learners. 


\section{METHOD}

The data were obtained from an English class of mixed-ability adult learners taught by a male teacher using audio-visual recording and observation. The results of the recording were transcribed to facilitate the preparation of data fragments of teacher-learner interaction. The observation was done by the researchers' sitting at the back of the classroom, taking field notes (Spradley, 1980:59) to get a comprehensive understanding of the corpus and its context.

The data were analysed using the techniques of qualitative data analysis from Miles and Huberman (1992:18), namely data reduction, data display, conclusion drawing, and interpretation. Fragments of the transcript which contain assertive acts were selected and organized. Assertive acts are utterances that describe some state of affairs. These are the kinds of speech acts which state what the speaker believes to be the case or not. Statements of facts, assertions, conclusions, and descriptions are some examples of the speaker representing the world as s/he believes it is (Yule, 1996:53). They were then displayed for the writer to be able to enumerate points, draw conclusions, and make interpretations.

\section{RESULTS AND DISCUSSIONS}

The utterances classified as assertive acts found in the data are presented in italics consisting of: informing, describing, exemplifying, explaining, concluding, summarizing, commenting, responding, extending, giving feedbacks, giving clues, announcing a topic, announcing a task, and controlling/shifting a topic.

\section{Informing}

Informing is a communicative function by which the $\mathrm{S}$ (speaker) gives information to $\mathrm{H}$ (hearer), assuming that $\mathrm{H}$ does not know of it. It is for the benefit of $\mathrm{H}$. As can be found in the data, there are two ways the $\mathrm{S}$ gives information to $\mathrm{H}$, i.e., by using complete affirmative sentences and by saying a phrase or a word. These ways are used several times by the teacher. The examples are presented in italics as follows:

Data 1:

Teacher (T) : Now, as you can see, I'm wearing (touching his dress with his right hand on the right side of the chest, looking at his dress) what is it?

Learners (Ls) : Batik

$\mathrm{T} \quad$ : Yes, batik

This is a new batik (still pinching his dress on the right side of his chest).

Ls I just bought it yesterday, special for you in this meeting (smiling widely). 
In that excerpt, utterances of informing acts were said by $\mathrm{T}$ using complete sentences to inform Ls that it is a new batik and that it was bought the day before. Sometimes, $\mathrm{T}$ informed the Ls by using a phrase or a word as follows:

Data 2:

T : What do babies do usually?

Ls : Cry

$\mathrm{T} \quad$ : Cry a lot, ya. Cry a lot (written on the whiteboard [henceforth, WB]) And then, what?

Learner 1 (L) : Smile a lot.

$\mathrm{T} \quad$ : Wear nappies, pampers (written on WB)

The informative utterance in the above extract is in the form of a phrase and a word to inform Ls that babies usually wear nappies or pampers as additional information besides crying a lot and smiling a lot.

That act carries information values in two different ways: substantially and linguistically. Substantial information means that Ls did not know that the batik was new and that it was bought the day before. That is new information that the T thought Ls did not know before. Linguistic significance means that Ls might already know the information that babies wear nappies/pampers, but they might not know how to say it in English. At least, at the time of speaking, the $\mathrm{T}$ thought that Ls were not aware of that information. Therefore, the $\mathrm{T}$ gave them more additional linguistic information.

\section{Describing}

Describing is a communicative function by which $\mathrm{S}$ says what someone/something is. To do this, $\mathrm{S}$ uses some linguistic forms: sentences and phrases. For example:

Data 3:

$\mathrm{T}$ : I have a picture here (bringing a piece of paper at his hand, but not showing the picture to the Ls)

I just want you to guess who he is?

He is a very popular celebrity from England.

He is a well-known comedian

...

He is often compared with Charlie Chaplin

He's famous with a man with a rubber face

Ls : Mr. Bean.

T : Mr. Bean. (showing the picture of Mr. Bean)

The $\mathrm{T}$ described Mr. Bean by mentioning his being a popular celebrity, a well-known comedian, famous for having a rubber face, and by comparing him with Charlie Chaplin. Based on the analysis of data, describing was done by $\mathrm{T}$ in the process of giving clues to Ls 
to be able to guess. The following excerpt is a guessing game where all Ls in the class described a picture to be guessed by one learner as a lone stranger.

Data 4:

T : OK, describe this over (showing a picture to the class, not to the lone stranger)

L1 : Son and daughters.

L2 : You married, and you have a lot of babies.

L3 : Like in Bali, you have four maybe: Made, Ketut, Nyoman.

L1 : You with your husband have how many ...

L4 : Nephew (using hand gestures, smiling)

$\mathrm{T}:$ No.

L4 : Children

Ls : Haaa (laughing and shouting)

$\mathrm{T}$ : Yes, good, give applause. (Ss clapping hands)

This excerpt represents a part of a guessing game done by Ls. The T showed a picture to the Ls in the class and asked them to describe it to one of them who was sitting in front of the class. The word to guess is "children." Learners described it by saying words related to it, such as son and daughters, and using sentences, like "You married and you have a lot of babies; Like in Bali, you have four maybe: Made, Ketut, Nyoman, and You with your husband have how many ...."

Comparing the two ways of describing, given by Ls and by T, we know that the main difference lies in the speech events in which the discourse is produced. Ls produced the utterances when they were engaged in a game activity, a sort of competition in which speed of response is required. It means that in the game, the quicker the participant could guess the word or phrase, the better. Therefore, Ls tend to give description rapidly, paying no attention to the completeness of sentences, using more isolated words and phrases, to give as many clues as possible so that the guesser could guess swiftly.

\section{Explaining}

Explaining is an act performed by $\mathrm{S}$ to clarify the meaning of a word/phrase to $\mathrm{H}$. This is done in several ways, e.g., by giving a sentence that clarifies the meaning of the word/phrase being explained by putting it in a sentence or by rephrasing it. For example:

Data 5:

T : What's put up with?

Anybody knows? Put up with? (facing the class)

To make easy to understand ( $\mathrm{T}$ switched on the Overhead Projector and put a picture on to explain it)

This is a man.

This man puts up with the children (looking at a picture on the screen)

You know? He has naughty children, but he gets, still gets along well with them. 
So, although they're naughty (pointing a picture on the screen), he still gets along with them.

L1 : Patient.

T : Yes, almost the same with the patient.

The italicized utterances are examples of T's explaining the phrase "put up" by using sentences that clarify its meaning. In the following excerpt, the phrase "turn down" was explained by giving its meaning and putting it in a sentence.

Data 6:

T : Although he knew that she loves him very much, he turned her down.

He turned her down, meaning he rejects.

He turned her down.

So, you love someone, and then he turned you down, meaning he rejects you.

Sometimes, explaining is also done by rephrasing the word or translating it into the native language.

Data 7:

T : "I'm looking forward to hearing from you soon, "meaning that you want your friend to reply to your letter soon.

Put up with somebody or something means to accept unpleasant behavior. To accept unpleasant behavior, or unpleasant situation, even though you do not like it

Although you don't like it, you accept it.

For example, I can put up with a house being untidy, but I don't like it to be dirty.

Saya bisa tahan dengan rumah yang tidak rapi, asalkan, asalkan jangan kotor

(Indonesian native language).

In the extract above, $\mathrm{T}$ explained the meaning of the phrase "look forward to" by rephrasing it in an equivalent sentence. After that, T explained the meaning of "put up with" by rephrasing it using more comprehensible sentences. Finally, he explained the phrase "put up with" by translating it into Indonesian, Ls' native language. He expected that by switching the code into the native language, Ls would get a clearer idea about the meaning of the target phrase.

\section{Exemplifying}

This is an act of $\mathrm{S}$ giving examples to $\mathrm{H}$ to clarify the meaning of a word/phrase. The lexical head acts usually used to do this are for example and like. Sometimes, however, $\mathrm{S}$ directly gives examples without using an explicit head act. Exemplifying is usually done within the process of explaining. That means examples are given to make the explanation clearer (see Data 7). 
The teacher gave examples to explain a word/phrase to learners. In the above extract, $\mathrm{T}$ used an example to clarify his explanation about the meaning of the phrase "put up" by putting it in a complete sentence.

\section{Concluding}

Concluding is different from summarizing. The former refers to making a statement based on the implied message of sentences, whereas the latter to a shorter restatement of a message. For example:

\section{Data 8:}

$\mathrm{T} \quad$ : So, people believe that my marriage, people believe that my marriage was blessed.

That is why three years after my marriage, my wife and I got an Australian scholarship and we went to Australia together with our children (fingers crossed)

Happy ending, ya?

After telling about his blessed marriage, T finally concluded by saying "Happy ending, ya?" In this case, T made the conclusion of his speech. Sometimes, T also concluded the learner's speech, as follows:

Data 9:

$\mathrm{T} \quad$ : Which one is busier? Mother or father usually? (hand/finger gestures)

L1 : (A male learner) Both

$\mathrm{T} \quad$ : Both ya?

Do you agree?

L2 : (A female learner) No.

T \& Ls : ha ha ha (laughed loudly)

$\mathrm{T} \quad$ : Mother is usually busier (pointing at WB)

The utterance "Mother is usually busier" is a conclusion of the previous response when a female learner did not agree that both father and mother were equally busy when the mother is expecting a baby. So, the question, "Which one is busier? Mother or father usually?" was answered by Thimself by making a conclusion based on the Ls' response.

In another case, the conclusion was stated using an explicit lexical expression, "I think ...." This can be seen in the following excerpt.

Data 10:

$\mathrm{T} \quad$ : OK. If you write a letter, and the end usually you write "I da da da to hearing from you soon."

$\mathrm{T}$ : If you want someone to reply to your letter, usually you write, "I da da da waiting for your

L6 : Waiting for..

$\mathrm{T} \quad$ : Yes, the synonym of waiting?

L1 : Look forward. (pointing to a learner, agreeing)

$\mathrm{T} \quad$ : Good! Look forward to (writing the phrase on the board). OK. (lifting up the screen) 
Look forward to (pointing the phrases on whiteboard facing the class)

I think you've already understood the meaning.

So, now, I'm giving you the matching task. (taking a handout from a table)

Looking at the data above, a conclusion was made by $\mathrm{T}$ based on the preceding utterances. First, T put the taught vocabulary "look forward to" in a context sentence, "If you want someone to reply your letter, usually you write, 'I da da da waiting for your'" Then, a learner guessed it by saying "waiting for." After that, T elicited its synonym, and one of the Ls responded "look forward." Based on the fact that a learner was able to provide the correct response, T finally concluded by saying, "I think you've already understood the meaning".

The conclusion was made based on the preceding utterances and treated as a basis for the following activities. Knowing that learners could mention the correct phrase and perhaps he remembered teaching it before, he drew such a conclusion. That is why, after inferring that learners had understood the meanings of the vocabulary, the teacher gave them a matching task.

\section{Summarizing}

As was stated before, summarizing is making a shorter restatement of the previous sentences. The following excerpt clarifies the point.

Data 11:

$\mathrm{T} \quad$ : OK. About the article. (turning around, making hand gestures)

Which one is the most important event, which one is the most important event in Rowan

Atkinson's life? (silence to give Ls thinking time)

What happened when he met Richard Curtis? (addressing a L. The class is silent)

They collaborated and finally they made $\mathrm{Mr}$ ? Mr. Bean.

Yes, the most important event in the Rowan Atkinson's life.

OK. Now, please do the gap filling. (approaching Ls)

After eliciting the most important event in Atkinson's life, Ls answered it (unfortunately it was not recorded), then $\mathrm{T}$ gave guidance and finally restated the main topic. Like a conclusion, making a summary is based on the preceding utterances and used as a basis for the following task. Therefore, after summarizing, $\mathrm{T}$ continued to order Ls to do the gapfilling.

\section{Commenting}

Commenting is an act of giving comments on the preceding utterances as in the following excerpt. 


\section{Data 12:}

$\mathrm{T} \quad$ : OK. So, this is about the life, life stages ya?

Where you undergo in your life, starting from babies, children, and the last is retired or

the last, the last is pass away.

Hopefully, you can live forever, hopefully.

But, it is impossible (smiling)

Talking about life stages, the teacher said that it started with babies, and the last is passing away. Then, he tried to give some jokes, "Hopefully, you can live forever." But, finally, he commented on his recent statement that it is impossible.

This comment was intended to neutralize the joke. That he said about the hope of living forever is just a joke because everybody knows that it is impossible. First, the $\mathrm{T}$ was serious when mentioning stages of life from babies to death. Then, he added jokingly by saying, "Hopefully, you can live forever, hopefully." Finally, he gave comments on this joke, remarking that it is impossible.

\section{Responding}

This is a communicative function by which $\mathrm{H}$ gives a response to S's utterance in the form of greetings, requests, or questions. To classify this function to the types of acts is a rather tricky matter. A greeting like "Good afternoon" is responded by another greeting; thus it can be categorized into expressive. The reply to another greeting, "How are you," however, i.e., "I'm fine," maybe included in assertive acts because it implies a statement of the physical and/or mental condition of the $\mathrm{S}$. The following is an example of responding to a request:

Data 13:

L1 : Please, your finger. (L requested T to remove his finger as it blocked the sight of some part of the picture)

$\mathrm{T}:$ : All right.

This is the teacher's response to the learner's request to remove his finger when it was blocking the sight of the picture. This can be classified as assertive because it implies that the teacher described some state of his affairs that he was all right to remove his finger not to block the sight of the picture.

There are some ways to respond to a question. The example of responding to a question can be seen in the following excerpt.

Data 14:

L7 : What is bald?

$\mathrm{T} \quad$ : It's like me (touching his head) 
(Ls were busy discussing in their groups for about 3.5 minutes. T monitored around, looking at them doing the task, moving from one group to another, always smiling when watching them seriously doing the task).

From the excerpt above, it is clear that responding may be in the form of gesture and verbal statements. When one of the Ls asked about the meaning of the word "bald," T responded to him by touching his head (fortunately, the teacher's head is bald) while saying It's like me. In that way, he did not need to explain its meaning by using a verbal definition. He just used gestures.

In that case, nonverbal response, in the form of T's touching his bald head, is efficient and effective in clarifying the meaning of the word "bald." Ls could immediately get the idea of its meaning, although $\mathrm{T}$ did not give verbal definition. In short, real objects and gestures are sometimes more efficient and effective in clarifying the meanings of certain words, especially concrete ones.

In the following extract, responding can also be in the form of a promise, as follows:

Data 15:

L3 : Tukang PAM. Please, copy it!

T : Yes, I'll copy it for you.

In the excerpt above, it is obvious that the response given by the teacher was in the form of a promise. When the learner requested the teacher to copy the material, the teacher responded to him by promising that he would copy it for him. Although it was a response to one learner's request, the analyst can infer that the promise was addressed to all learners in the class. It means the T promised to copy the material and would give it to all of them, not only to the one who was requesting. Otherwise, it would be regarded as unfair.

\section{Extending Utterances}

Extending utterances means the $\mathrm{S}$ adds some more words, phrases, or sentences in addition to the utterances previously produced. This can be divided into two types: extending other's utterances and extending the speaker's utterances.

Data 16:

T : What do babies do usually?

L1 : Cry

T : Cry a lot, ya. Cry a lot. (written on WB)

Above is an example of extending other's utterances. That is, a learner responded to the T's question saying, "Cry." Then, the teacher extended it by saying, "Cry a lot, ya. Cry a lot" The following is an example of a teacher's extending his own utterance. 


\section{Data 17:}

T : He was happy because he has a child and unhappy because he spends a lot of money. Spend much money ya?

For children, ya? And you (pointing with the palm of his left hand) got many things to do usually, ya?

The above utterance is an example of a teacher's extending ideas by adding more information relevant to the previous statement. Talking about marriage, a learner said that it might make us happy and unhappy. When he focused on the cause of unhappiness, i.e., spending much money, the teacher not only echoed the learner's utterance but also added more points to extend the idea of the causes of unhappiness, i.e., spending much money for children and there are usually more things to do.

\section{Giving Feedback}

Giving feedback is an act done by $\mathrm{H}$ to give comments on what the $\mathrm{S}$ says. There are some kinds of feedback: confirming, disconfirming, and emphasizing. Confirming is the type of feedback given by the $\mathrm{H}$ when the S's utterance is regarded correct and accepted by $\mathrm{H}$. On the other hand, disconfirming is the feedback given when S's utterance is considered not correct and rejected. Emphasizing is feedback given to emphasize the correctness of the S's answer and can be affiliated under the act of confirming. The forms mostly used as found in the data are repetition and reformulation. The examples can be seen in the following excerpt.

Data 18:

T : What is it? Have wife or ...

L2 : Grey-haired.

$\mathrm{T}$ : Yes, grey-haired.

How about group one?

What children do usually?

L1 : Switch and? Play computer.

$\mathrm{T} \quad$ : They switch and play a computer game.

$O K$. I think this is quite right (talking to group one)

That is an example of confirming by accepting and followed by a full repetition of the previous utterance. Confirmation is also done by the $\mathrm{H}$ in response to what the $\mathrm{S}$ says by reformulating the answer in the form of phrases and reformulated into a complete sentence. Acceptance is indicated by the utterance coming after completed reformulation to confirm that the answer is quite right.

An example of disconfirming is by repeating the answer using question intonation and followed by negative feedback.

Data 19:

$\mathrm{T} \quad$ : How about the second picture? (showing a picture on the screen) 
L5 ; Develop

T : Develop? Almost right.

L1 : Develop. Grow up.

T : Grow up? No.

What does the mother do? (pointing a picture on screen) From babies, children, teenagers, and then a... adult. The mother ... bla bla bla

L1 : Raise

T : Ya, raise? Raise up or?

"Develop?" is a kind of disconfirming in the form of repeating the S's word, but pronounced with final rising intonation indicating a question. The teacher was questioning the answer, stimulating the learner to rethink his answer more deeply, and then followed by a judgmental statement, "Almost right." The teacher used the word "almost" to mitigate his judgment and to avoid the learner's feeling of being offended. By saying "almost right," the teacher expected that the learner was still courageous to come up with another answer. That was effective as indicated by the fact that it is, then, followed by another answer. This time, the teacher was more strongly decisive, i.e., by repeating the learner's answer then followed by strong judgment "No."

That is intended to prevent Ls from making another error. To do that, the $\mathrm{T}$ also gave further help by asking leading questions, "What does the mother do? From babies, children, teenagers, and then a ... adult. The mother ... bla bla bla." This help seemed effective, as indicated by a better answer given by the learner. Although it was not accurate yet, the word "raise" was closer to be correct because the expected answer was "bring up."

Sometimes, feedback is expressed by exposing H's answer to other Hs to get a response from them. For example:

Data 20:

T : How about number one?

L6 : I was grown up to pay attention on health and education.

$\mathrm{T} \quad$ : I was grown up to pay attention on health and education (reading handout) Is it right?

L1 : No.

I was brought up to ...

$\mathrm{T} \quad$ : Yes. That's right, brought up.

I was brought up to pay attention on health and education.

First, the learner's answer was repeated fully then continued by feedback in the form of a question addressed to other Ls. That was intended to disconfirm the answer. However, it was done indirectly, i.e., by addressing it to other Ls so that all of them were involved in the thinking process. That is a kind of delayed feedback, not necessarily given by the teacher, but by other learners. 
After being disconfirmed, one of the learners gave the correct answer. This final answer was correct; therefore, it was confirmed by the teacher. Then, the correct answer was repeated partially, i.e., only the core phrase, and followed by reformulating the whole utterance. In short, when the answer is correct, the confirmation is in the forms of its repetition, fully or partially, and/or positive feedback. When the answer is incorrect, the feedback may be questioning it, addressing it to other learners, and/or disconfirming using mitigation.

\section{Giving Clues}

Giving clues is an act performed by $\mathrm{S}$ to lead the $\mathrm{H}$ towards the destination intended by $\mathrm{S}$. This is usually done by presenting questions leading to what is intended. For example:

Data 21:

T : OK. When you have babies, and then? ("babies" written on WB)

What else? (facing to class)

Children, and teenagers. (written on WB)

What else? Did you remember?

L1 : Married couple (written on WB)

$\mathrm{T} \quad$ : Yes, married couple, and then? (written on WB)

In talking about life stages, T wanted to elicit the word "retired" from Ls. To achieve that purpose, he led them by asking questions and answering them, step by step, until Ls got the idea of what was intended. Due to time efficiency, however, in that very context, $\mathrm{T}$ finally provided the intended word because the word seemed to be beyond their competence.

\section{Announcing a Topic}

Announcing a topic is an act by which the $\mathrm{S}$ mentions the topic to deal with. This is performed by using the head act of announcement as follows:

Data 22:

T : OK. Life stages. (written on WB)

This is the context of our discussion today (pointing to whiteboard). About "Life stages"

What do babies do usually?

Sometimes, announcing a topic is preceded by the statement of its context, and stated implicitly in combination with informing what the teacher is going to do with the topic.

Data 23:

T : OK. Talking about Mr. Bean, I will give you a short biography of Mr. Bean

In this second example, $\mathrm{T}$ announced the topic by relating his statement with the point discussed previously. That was supposed to be the context to which the topic was connected. The phrase "Talking about Mr. Bean, ..." indicated that the teacher had just talked about Mr. 
Bean. Concerning that, he, then, announced what he was going to do, i.e. telling the Ls the biography of Mr. Bean. In sum, it could be inferred that T announced the topic as if he said, "We are going to talk about the biography of Mr. Bean."

\section{Announcing a Task}

Announcing a task is an act when $\mathrm{S}$ says the task or the activity to conduct. A task is an activity that is conducted by classroom participants as a part of the lesson stages. To do this, the teacher announced it so that learners knew what they were going to do. It is then followed by giving instructions, which is about how to do it. An example of announcing a task is as follows.

Data 24:

$\mathrm{T} \quad$ : I just want to warm up you at the beginning of the lesson

So, we are doing a guessing game (making hands gestures)

So, I will show you some pictures (as if holding a picture), and then you guess the picture.

As can be seen in the above excerpt, a task was announced. Beforehand, T stated the purpose of the activity, that is to warm up the learners before starting the lesson. Then, he announced the task in the form of a guessing game. After announcing the task, moreover, T presented some detailed procedures of how to conduct the activity. Even more detailed rules of the game were presented afterward. The example is that in performing the guessing game, the teacher showed a picture, and the learners described it for the contestant to guess what was being described.

\section{Controlling/Shifting a Topic}

Controlling a topic is an act manifested in the form of an utterance produced by $\mathrm{S}$ to indicate that a new point of discussion (topic) is introduced. It implies that interlocutors are engaged in talking about a topic then $\mathrm{S}$ mentions a new topic shifting the previous one.

Data 25:

$\mathrm{T} \quad$ : OK. Is your prediction correct?

How many words are correct? (smiling, putting hands in pockets, approaching Ls)

L1 : Only one.

T : Only one? He he he. Only one (smiling)

$O K$. About the article. (turning around, making hand gestures)

Which one is the most important event, which one is the most important event in Rowan Atkinson's life? (silence for thinking time)

The above utterance is an example of an utterance indicating S's control or shift of topic. First, the communicants were talking about the number of words predicted correctly, but then the $\mathrm{T}$ moved away from that topic and brought into a new topic about the content of the article. By saying, "OK. About the article" the T seemed to hint to stop talking about the 
number of words predicted, demonstrated by the use of a discourse marker "OK"; and then, led the Ls to focus on something different, i.e., the content of the article. That was evident by the next utterance, which was asking about the most important event in Rowan Atkinson's life.

\section{Discussion}

In the context of EFL, the performance of assertive acts by the teacher is significant to promote not only the learners' target language acquisition but also their cognitive development.

Based on the analysis of the data, it is the teacher who gives information and not the other way around because $\mathrm{T}$ is in the position of being more knowledgeable than Ls. The giving of conceptual as well as of linguistic information by $\mathrm{T}$ to Ls is consistent with the idea of teaching principle, i.e., transfer of ideas from $\mathrm{T}$ to Ls, although that does not necessarily mean that learning takes place.

Informing is done by $\mathrm{T}$ using verbal and body language. T's bodily behavior is also useful to maximize Ls' perception of the language's meaning. For Ls to perceive new information better, T not only said the words but also wrote them on the whiteboard. In that way, Ls knew the meanings of baby-related words. They recognized their forms more effectively because they perceived them through multimodal (Moreno \& Mayer, 2007) ways of both auditory and visual senses.

In giving a description, the teacher needs to make communication effective by providing as much linguistic input as possible. He gave perfectly complete sentences while giving clues to the learners so that they understand who is being described. So, there are twofold purposes the teacher wants to serve in describing, i.e., giving clues as clear as possible in order for learners to understand what is being described, and providing good linguistic models so that learners could perceive. That is the reason why the teacher gives descriptive-complete sentences.

Explaining is an act that is likely performed by the teacher intended to improve learners' knowledge of the meanings of vocabulary. There are some ways used by $\mathrm{T}$ to explain the meanings of vocabulary, such as rephrasing or reformulating, putting the target vocabulary in context, giving definition, and translating or code-switching. The use of such a range of strategies is intended to help Ls understand the concepts or meanings and enrich their knowledge of vocabulary. Exemplifying is an act where the teacher gives examples to clarify a certain point. This is important to help the learners get a clearer understanding of a concept 
because by having examples, learners will get less abstraction of the concept; hence, they get a clearer idea about it.

Summarizing is performed to restate an explicit idea in a shorter version so that the learners can obtain and preserve an insight deeper in their memories; hence, it is easily retrieved when needed. Almost similar to that, concluding is more comprehensive, covering up all implicit ideas regarding their relevant contexts. Therefore, it is more insightful and meaningful.

Teacher's responding to learners, either verbally or behaviorally, is psychologically significant. When responded properly, learners feel they are attended and their needs satisfied, thus, increasing their learning motivation and involvement in the learning process. Extending is significant in several ways. First, it is useful to provide richer linguistic input to the learners, which departs from learners' own utterances. Starting from learners' production of language, the teacher extends or adds more words, phrases, or sentences to give more complete utterances. That is functional as a model to imitate or input to acquire. Second, extending is useful to complete the information given by the learner. The teacher might think that the information is not complete, thus needing to be completed. Another possibility is that the information might have been complete already, but the teacher thinks there is still some room to supplement. So, an extension can have a complementary function. Third, extending may be done by the teacher to overcome the information breakdown, which is caused by the lack of learners' competence.

Giving feedback is classified as assertive because it implies the statement of the state of affairs whether the $\mathrm{H}$ agrees/accepts the answer or disagrees/rejects it. In a behavioristic point of view, giving feedback is recommended because this is intended to reinforce the response given by the learners towards the stimuli provided by the teacher (Brown, 2007). Confirming is a positive reinforcement, whereas disconfirming is a negative reinforcement. By confirming, the teacher wants that the learners are accustomed to always providing good and correct responses, which in the long run will form a good habit. By disconfirming, moreover, the teacher expects that the learners are prevented from making wrong answers, thus saving them from the formation of a bad habit.

Giving clues is another important act performed by the teacher. This stimulates the learners to get involved in the thinking process. In giving clues, there is some significance why the teacher prefers to give clues rather than just directly telling the word. First, that is intended to train learners to think in a systematically gradual way. Second, in that way, learners are thinking actively to find answers by themselves - a way to encourage and 
practice discovery learning (Bruner, 1966). Third, discovering the words by learners themselves will likely be memorable in the longer-term than being told. Fourth, learners are actively involved in the thinking process.

By announcing the topic, the teacher is able to attract learners' attention to focus on the topic being dealt with. That is important because in that way, learners get an idea about what they are talking about, hence facilitating their comprehension of the materials discussed. Presenting a topic represents an establishment of a frame to facilitate understanding of the general idea. That is useful to understand its more detailed points. Brown and Yule (1983) suggest that the recognition of given (old) information is facilitative for understanding new information.

Announcing a task is also normally done by a teacher. This is important to start an activity so that the learners focus their attention on the task, know what to do, and understand the objectives to achieve. Hence, learning is likely to be effective.

The act of shifting and controlling a topic is significant in determining the flow of the lesson. The depth and/or the breadth of the lesson contents by which the teacher develops learners' knowledge and competence are/is determined by his creativity and initiative in performing this act. A competent teacher can shift from one topic to another within the relevant frame of a greater theme, thus enriching and broadening the knowledge of the learners. In doing this, however, the teacher should be very careful in order not to be tempted to stray from the core point of the lesson. Otherwise, the lesson will be drifting away from the mainstream; hence the achievement of the lesson's main aim is hardly possible.

\section{CONCLUSION}

The study of teacher's classroom discourse is significant to unfold the communication phenomenon within pedagogical contexts. This information can be taken into account in finding ways to increase the effectiveness of language teaching and learning practices. Assertive acts performed by teachers are only a part of the whole teacher discourse. They serve a range of pedagogical purposes, such as to provide information, to provide linguistic models, to reinforce communicative behavior, to manage classroom proceedings, and to establish effective learning condition. To complement this finding, furthermore, it is important to conduct further studies to uncover other speech acts, directive, expressive, commissive, and declarations (Searle, 1979) in the classroom discourse. 


\section{REFERENCES}

Blum-Kulka, S. (1998). Discourse pragmatics. In T. A. van Dijk (ed.) Discourse as social interaction. London: SAGE Publications

Brown, G. \& Yule, G. (1983). Discourse analysis. Cambridge: Cambridge University Press

Brown, H. D. (2007). Principles of language learning and teaching. New York: Pearson Education

Bruner J. (1966). Toward a theory of instruction. Cambridge, MA.: Harvard University Press

Ellis, R. (1986). Understanding second language acquisition. Oxford: Oxford University Press

Halliday, M. A. K. (1975). Learning how to mean: Explorations in the development of language. London: Edward Arnold

Krashen, S. D. (1985). The input hypothesis: Issues and implications. London: Longman

Miles, M. B. \& Huberman, A. M. (1992). Analisis data kualitatif (Qualitative Data Analysis. T. R. Rohidi, Trans.). Jakarta: UI Press

Moreno, R. \& Mayer, R. (2007). Interactive multimodal learning environments. Educ Psychol Rev 19, 309-326 (2007). https://doi.org/10.1007/s10648-007-9047-2

Searle, J.R. (1979). The classification of illocutionary acts. Language in society. 5: 1-24

Spradley, J.P. (1980). Participant observation. N.Y.: Holt, Rinehart \& Winston

Stubbs, M. (1983). Discourse analysis. Chicago: The University of Chicago Press

Yule, G. (1996). Pragmatics. Oxford: Oxford University Press 